\title{
Electrosprayed mucoadhesive alginate- chitosan microcapsules for gastrointestinal delivery of probiotics
}

Article

Accepted Version

Creative Commons: Attribution-Noncommercial-No Derivative Works 4.0

Ta, L. P., Bujna, E., Kun, S., Charalampopoulos, D. ORCID: https://orcid.org/0000-0003-1269-8402 and Khutoryanskiy, V. V. (2021) Electrosprayed mucoadhesive alginate-chitosan microcapsules for gastrointestinal delivery of probiotics. International Journal of Pharmaceutics, 597. 120342. ISSN 0378-5173 doi: https://doi.org/10.1016/j.ijpharm.2021.120342 Available at https://centaur.reading.ac.uk/97503/

It is advisable to refer to the publisher's version if you intend to cite from the work. See Guidance on citing.

To link to this article DOI: http://dx.doi.org/10.1016/j.ijpharm.2021.120342

Publisher: Elsevier

All outputs in CentAUR are protected by Intellectual Property Rights law, including copyright law. Copyright and IPR is retained by the creators or other copyright holders. Terms and conditions for use of this material are defined in the End User Agreement. 


\section{CentAUR}

Central Archive at the University of Reading

Reading's research outputs online 
Electrosprayed mucoadhesive alginate-chitosan microcapsules for gastrointestinal delivery of probiotics

Linh Phuong Ta ${ }^{1,2}$, Erika Bujna ${ }^{2}$, Szilárd Kun², Dimitris Charalampopoulos ${ }^{3}$, Vitaliy V. Khutoryanskiy ${ }^{1 *}$

${ }^{1}$ Reading School of Pharmacy, University of Reading, Whiteknights, PO Box 224, Reading RG6 6DX, United Kingdom

${ }^{2}$ Institute of Biosystems Engineering and Process Control, Faculty of Food Science, Szent István University, Ménesi út 45, H-1118 Budapest, Hungary

${ }^{3}$ Department of Food and Nutritional Sciences, University of Reading, Whiteknights, Reading, Berkshire, RG6 6DZ, United Kingdom

*Corresponding author:

Prof V. V. Khutoryanskiy

Email address: v.khutoryanskiy@reading.ac.uk

Telephone: +44(0) 1183786119

Fax: +44 (0) 1183784703

1

\begin{abstract}
Besides viability protection, a sufficiently prolonged gastrointestinal retention of probiotics has emerged as critically important in improving the functional effectiveness of gastrointestinal delivery of these microorganisms. In this work, we formulated pure, resistant starch-reinforced and chitosan-coated alginate microparticles using an electrospray technique and evaluated their performance as mucoadhesive probiotic formulations for gastrointestinal delivery. In addition, we designed and successfully validated a novel experimental set-up of in vitro wash-off mucoadhesion test, using a portable and low-cost USB microscope for fluorescence imaging. In our test, pure chitosan microparticles (positive control) exhibited the greatest mucoadhesive property, whereas the alginate-resistant starch ones (negative control) were the least retentive on a gastric mucosa. These electrosprayed formulations were spherically shaped, with a size range of $30-600 \mu \mathrm{m}$ (60 - $1300 \mu \mathrm{m}$ with chitosan coating). Moreover, model probiotic Lactobacillus plantarum loaded in
\end{abstract}


alginate-starch formulations was better protected against simulated gastric conditions than in alginate ones, but not better than in the chitosan-coated ones.

Keywords: electrospraying; microcapsules; probiotics; mucoadhesion; alginate; chitosan

\section{Introduction}

Probiotics are living microorganisms present in human gastrointestinal tract that can promote health by preventing or alleviating disorders and diseases when administered in sufficient (live) amounts (FAO/WHO, 2001). These specific microorganisms are usually consumed as dietary supplements or as fortified foods, due to their proposed beneficial effects on human gastrointestinal health and immune system. For exerting their therapeutic functions, the most generally suggested minimal amount of viable probiotics to be consumed is $10^{6}-10^{7} \mathrm{CFU}$ (colony forming unit) per $\mathrm{g} / \mathrm{mL}$ of a probiotic product (Nazir et al., 2018; Yao et al., 2020). Minelli and Benini (2008) demonstrated a necessary probiotic survival at a minimum of $10^{6} \mathrm{CFU} / \mathrm{mL}$ of digesta after the gastric challenge and a minimum presence of $10^{8} \mathrm{CFU} / \mathrm{g}$ of end digesta in the colon.

However, probiotics incorporated in food products tend to lose a significant number of their viable cells during processing, storage and the passage through the gastrointestinal tract. In this context, the therapeutic functionality of probiotic supplements has also been shown to be questionable for this same reason (Corona-Hernandez et al., 2013; Dodoo et al., 2017; Fredua-Agyeman et al., 2015; Heidebach et al., 2012). Microencapsulation technology has emerged to support the survival of probiotics against harsh environmental factors encountered during processing and their transit through the gastrointestinal tract and to target their delivery to the colon to ensure probiotic colonisation (Yao et al., 2020).

There has been a significant progress on probiotic microencapsulation using extrusion, et al., 2013). However, some shortcomings in these methods are still present in terms of producing particles with all the necessary characteristics, using technologies that are suitable for industrial applications. In recent years, the concept of using electrospraying (electrohydrodynamic atomisation) for microencapsulation has been reported a few times (Coghetto et al., 2016; GómezMascaraque et al., 2017; Librán et al., 2017; Zaeim et al., 2017, 2018). In this technique a polymer solution, while passing it through a needle, becomes charged by the presence of high potential electric field applied at the tip of the needle and is consequently atomised into finer liquid droplets. These electrified droplets then fall towards an oppositely charged metallic collector, with which microparticles can be formed.

Probiotic microencapsulation using electrospraying can offer several advantages, considering its mild processing conditions, high production yield and good industrial scalability as compared to the above-mentioned conventional methods. This technique also allows the preparation of particles in micron-size range, making them suitable for incorporation in some specific commercial probiotic products (Bhushani et al., 2017; Wang et al., 2019). 
Previous studies have reported excellent potential of calcium alginate as a material for microencapsulating and protecting probiotics (Cook et al, 2012). However, several considerable limitations have also been identified for alginate-based microcapsules, including their high porosity (Chen and Chen, 2007; Gombotz and Wee, 2012; Martín et al., 2015; Smidsrød and Skjåk-

77 Bræk, 1990).

Coating alginate with chitosan has been explored in some studies to resolve these problems (Chávarri et al., 2010; Cook et al., 2011; Nualkaekul et al., 2012). In addition, inclusion of prebiotic compounds (often oligosaccharides) into the alginate matrix or co-encapsulation with a range of biopolymers have been proposed as alternative for enhancing the functional effects of encapsulated probiotics (Ashwar et al., 2018; El-Abd et al., 2018; Krasaekoopt et al., 2003; Krasaekoopt and Watcharapoka, 2014; Sabikhi et al., 2011; Samedi and Charles, 2019; Sultana et al., 2000). Prebiotics are the group of non-digestible food nutrients that can serve as selective substrates for the probiotics (and beneficial gut microbiota), thereby conferring positive effects on human health (Davani-Davari et al., 2019).

Additional approach for enhancing the efficiency of gastrointestinal delivery of probiotics is to formulate microcapsules with mucoadhesive coating/matrix materials, ensuring their sufficiently longer residence time, thus better bioavailability of probiotics in the gastrointestinal tract (Alli et al., 2011; Cook et al., 2012; Singh et al., 2012; van Tassell and Miller, 2011).

In this study, we have used the electrospraying technique to produce microcapsules containing Lactobacillus plantarum for gastrointestinal delivery. Several types of microcapsules were prepared and evaluated, including chitosan-coated and uncoated calcium alginate capsules as well as microcapsules formulated as alginate mixture with resistant starch (prebiotic). These capsules were characterized using laser light diffraction and fluorescent microscopy and assessed in terms of the encapsulated bacteria survival, in vitro simulated gastric digestion and in vitro gastric mucosal retention. Additionally, a novel, simple and cheap fluorescence imaging-based set-up was designed to test the mucoadhesive properties of these microcapsules.

\section{Materials and methods}

\subsection{Materials}

The model probiotic strain of Lactobacillus plantarum NCDO 1752 used in this study was from the culture stock collection of National Collection of Dairy Organisms (NCDO), UK. Sodium alginate was obtained from SAFC Supply Solutions (St. Louis, MO, USA). Resistant starch (unmodified, raw potato-originated) was purchased from a local health supplement retailer (Reading, UK). Chitosan (low molecular weight, 75-85\% deacetylated, 50-190 kDa), sodium fluorescein (Na-Fluo), fluorescein isothiocyanate (FITC), fluorescein isothiocyanate-dextran (FITC-dextran; MW 3000-5000 Da) and phosphate-buffered saline (PBS) in tablet form were purchased from Sigma Aldrich (Gillingham, UK). Calcium chloride and sodium chloride were received from Fisher Scientific (Loughborough, UK). De Man, Rogosa and Sharp broth (MRS broth) and bacteriological agar were from Oxoid (Hampshire, UK). Deionised water was used for 
the preparation of all solutions. All solutions (without containing microorganism) and glassware related to microbiological experiments were sterilised at $121^{\circ} \mathrm{C}$ for $15 \mathrm{~min}$ with an autoclave.

\subsection{Bacterial culture preparation and cell enumeration}

Fresh Lactobacillus plantarum cultures were prepared by transferring a stock culture from an agar slant into MRS broth and reactivating it for $16-24 \mathrm{~h}$ at $37^{\circ} \mathrm{C}$. Bacterial growth was checked using turbidity (optical density, $\lambda=600 \mathrm{~nm}$ ) of this culture medium. After this period, the cells were collected by centrifugation at $10,000 \mathrm{rpm}$ for $10 \mathrm{~min}$ at $4^{\circ} \mathrm{C}$ (Thermo Scientific Multifuge Refrigerated Centrifuge, UK), and stored in sterile phosphate-buffered saline (PBS) solution at $4^{\circ} \mathrm{C}$ until further usage. Viable numbers of $L$. plantarum cells in any cultures (or samples) were determined according to the plating method described by Miles et al. (1938). Briefly, $3 \times 20 \mu \mathrm{L}$ droplets of the bacterial culture were placed on a sufficiently dried MRS agar plate and left to absorb for around 15-20 min. CFUs (colony forming units) of the inoculated bacteria were counted on the MRS agar plate after incubating these agar plates for $1-2$ days at $37^{\circ} \mathrm{C}$. All the $\mathrm{CFU}$ values were expressed as log values.

\subsection{Preparation of unloaded microcapsules}

Gel microparticles were produced by the electrospraying technique using a Spraybase ${ }^{\circledR}$ device (Avectas Ltd., Ireland) consisting of an air compressor, high voltage and flow rate controlling compartments (Figure 1). Applied voltage was within the range of $7-12 \mathrm{kV}$, depending on the lowest possible level that induced spraying. The pressure was set at 1 bar and the distance between the tip and the collector was $10 \mathrm{~cm}$. The feed solutions were composed of $2 \%(\mathrm{v} / \mathrm{w})$ alginate and $2 \%-2 \%(\mathrm{v} / \mathrm{w})$ alginate-resistant starch. These solutions were pneumatically pumped through the high voltage emitter needle $(19 \mathrm{G})$ and electrosprayed into a $0.05 \mathrm{M} \mathrm{CaCl}_{2}$ solution. The particles were then left to harden in this solution for $30 \mathrm{~min}$ before their isolation. The particles were washed with and kept in deionised water. Pure chitosan particles were also fabricated by electrospraying of $2 \%(\mathrm{w} / \mathrm{v}$ ) chitosan (in $0.1 \mathrm{M}$ acetic acid) solution into $2 \mathrm{M} \mathrm{NaOH}$ solution (at $16 \mathrm{kV}$ ). The particles were collected by centrifugation at $10,000 \mathrm{rpm}\left(4{ }^{\circ} \mathrm{C}\right.$ for $\left.10 \mathrm{~min}\right)$ and were handled with a help of a syringe with sterile $30 \mathrm{G}$ needle. Pure chitosan particles were not used for encapsulation of probiotic bacteria but were useful as a positive control in the mucosal retention studies. 


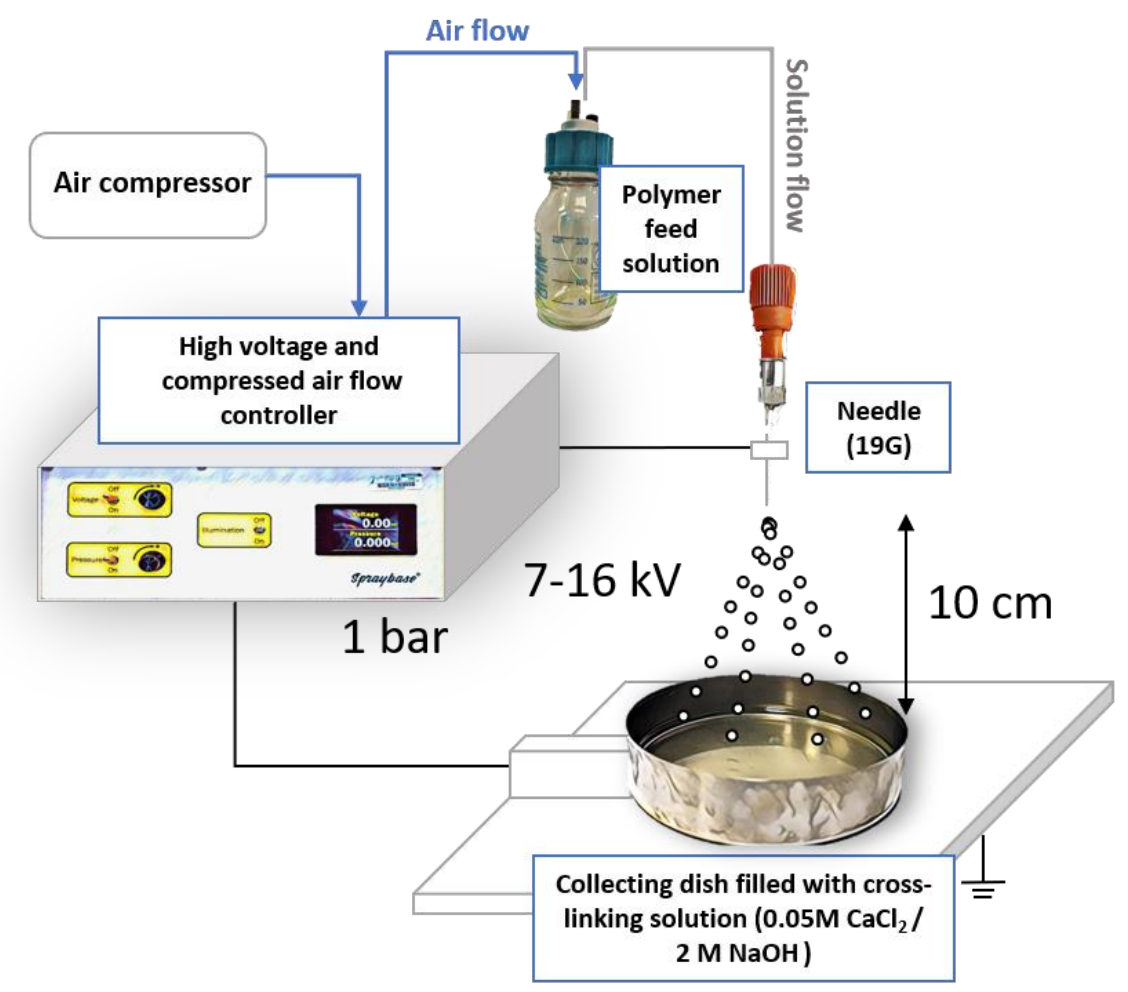

145 Fig. 1. Schematic diagram of the electrospray system used

\subsection{Coating of alginate microcapsules with chitosan}

147 To form chitosan coating layer, $0.5 \mathrm{~g}$ of alginate microcapsules was placed and agitated in $0.2 \%$ 148 (w/v) chitosan solution (acidified with $0.1 \mathrm{M}$ glacial acetic acid) for $30-60 \mathrm{~min}$ at $100 \mathrm{rpm}$. In the 149 case of the microcapsules loaded with bacteria, the $\mathrm{pH}$ of the chitosan solution was adjusted to $\mathrm{pH}$ 1506 with $1 \mathrm{M} \mathrm{NaOH}$ and then microfiltered through a Whatman® Grade 4 filter paper. This resultant 151 solution was autoclaved before the coating step.

\subsection{Preparation of fluorescently-labeled microcapsules}

153 Fluorescently-labeled alginate and alginate-starch microcapsules were prepared by electrospraying 154 polysaccharide solutions containing $0.1 \%(\mathrm{w} / \mathrm{v})$ sodium fluorescein; in the case of the 155 mucoadhesion study, 0.1\% (w/v) FITC-dextran was used. Chitosan was labeled with FITC using 156 the protocol described in our previous study (Cook et al., 2011). Chitosan-based particles used in 157 the mucoadhesion study were prepared from chitosan labeled with $0.1 \%$ (w/v) FITC.

\section{2.6. Microencapsulation of bacteria}

159 In order to produce the above-mentioned microcapsules loaded with L. plantarum, the viable 160 bacterial culture, prepared as described in Section 2.2, was first mixed with sterile polymer solution 161 at a volume ratio of 1:9. The mixture was then brought to electrospray $(7 \mathrm{kV}, 1 \mathrm{bar}, 10 \mathrm{~cm})$, 162 followed by harvesting with centrifugation $\left(10,000 \mathrm{rpm}, 4^{\circ} \mathrm{C}, 10 \mathrm{~min}\right)$ and double washing with 
sterile PBS. The bacteria-loaded microcapsules were suspended in sterile PBS and stored at $4^{\circ} \mathrm{C}$ for further use.

\subsection{Characterisation of microcapsules}

In order to image and assess the properties of the produced microcapsules fluorescence microscopy (Leica MZ10F, UK) was carried out using an ET-GFP filter. Images were taken with an exposure time of $57 \mathrm{~ms}$ for sodium fluorescein-loaded samples and $100 \mathrm{~ms}$ for FITC-labelled samples, using the pseudo colour wavelength of $520 \mathrm{~nm}$ and adjusting a slight black/white level correction. The ImageJ software (version 1.52a) was used to analyse the images in terms of fluorescent pixel intensity and physical dimensions related to the particles.

The particle size distributions and sizes of each microcapsule type were based on 5 replicates of laser light diffraction analysis using a Metasizer 3000 instrument (Malvern Instruments, Malvern, UK) with the help of a Hydro Medium Volume dispersion unit. Analyses were conducted with particles dispersed in deionised water $[10 \%(\mathrm{w} / \mathrm{v})]$. The particle refractive index, dispersant refractive index and absorption index value were $1.4,1.33$ and 0.1 , respectively. The volumeweighted mean diameter (D [4,3]) and the width of the size distribution (span) were determined according to the following equations (ASTM Standard E799-03, 2015; Resch-Genger, 2008):

$$
\begin{aligned}
& D[4,3]=\frac{\sum d_{i}^{4} \cdot n_{i}}{\sum d_{i}^{3} \cdot n_{i}} \\
& \text { Span }=\frac{d_{v 0.9}-d_{v 0.1}}{d_{v 0.5}}
\end{aligned}
$$

where $d_{i}$ is the diameter and $n_{i}$ is the number of the $i$-th particles; $d_{v 0.9}, d_{v 0.1}$ and $d_{v 0.5}$ (median) represents the diameter, below which the $90 \%, 10 \%$ and $50 \%$ of the population lies, respectively.

Microscopic images of particles were also generated using the Malvern Morphologi 4 static automated image characterisation device.

\subsection{Viability of encapsulated bacteria and encapsulation yield}

Encapsulation yield, representing a measurement of the efficacy of entrapment and survival of viable cells during the electrospray-based encapsulation process, was calculated as suggested by Martin et al. (2013):

where $\mathrm{N}$ is the number of viable cells detected in the resultant microcapsules and No is the initial number of viable (unencapsulated) cells mixed with the feed polymer solution used for electrospraying process. To determine the $\mathrm{N}$ value, entrapped bacteria were released by placing and agitating (15 min, $1000 \mathrm{rpm}$ ) the microcapsules in $0.1 \mathrm{M}$ phosphate buffer ( $\mathrm{pH} 7.5)$, then the released bacteria were enumerated using the surface drop-based plating method described in Section 2.2. 


\subsection{Viability of free and microencapsulated bacteria after exposure to simulated gastric fluid}

200

201

202

203

204

205

206

207

208

209

210

211

212

213

214

215

216

217

218

219

220

221

222

223

224

225

226

227

228

229

230

231

232

233

234

235

236

237

This study was carried out based on the procedure described by Cook et al. (2011), with some modifications. First, $0.05 \mathrm{~g}$ bacteria-loaded microparticles or $0.1 \mathrm{~mL}$ of free cell suspension were added to $0.9 \mathrm{~mL}$ microfiltered $(0.22 \mu \mathrm{m})$ simulated gastric fluid (SGF) which was prepared by dissolving $0.2 \%(\mathrm{w} / \mathrm{v}) \mathrm{NaCl}$ in deionised water, then adjusted to $\mathrm{pH} 2$ with $\mathrm{HCl}$ solution. The samples were then incubated for $1 \mathrm{~h}$ and $2 \mathrm{~h}$ at $37^{\circ} \mathrm{C}$. After each incubation time, SGF was separated using centrifugation $\left(10,000 \mathrm{rpm}, 4^{\circ} \mathrm{C}, 10 \mathrm{~min}\right)$, followed by resuspending bacteria or agitating (1000 rpm, $15 \mathrm{~min}$ ) the microcapsules in $1 \mathrm{~mL}$ PBS until their complete disintegration. Survived bacterial numbers of each sample were enumerated using the method described in Section 2.2.

\subsection{Retention of microcapsules on mucosal surfaces}

The mucoadhesive properties of microcapsules on gastric mucosal surface were examined by using the modified fluorescence flow-through retention test developed earlier by the Khutoryanskiy group (Cook et al., 2018; Kaldybekov et al., 2018; Porfiryeva et al., 2019). Retention on mucosal surfaces in this case depends on mucoadhesive properties of microcapsules and represents their ability to retain on the target mucosal surface over some period of time while washed with simulated gastric fluid. This retention was monitored and investigated through the microscopic imaging of the fluorescently labelled microcapsules on the mucosal surface at regular time intervals. The main modification made in our study was that the retention was observed under a 1080P 1000X Zoom HD 8LED Digital USB Microscope Magnifier Endoscope Video Camera. In this case, a Winzwon UV Torch was used as an external light source to illuminate the fluorescently-labelled microparticles, whereas the internal light source of the microscope itself was switched off for the whole duration of experiment to increase the fluorescent intensity. The AmCap ver. 9.0 software was used for recording the images of the samples. The retention studies were conducted using the experimental set-up shown in Figure 2.

Porcine stomachs were collected from a local abattoir (North Camp, UK) in a cold storage box ( $4^{\circ} \mathrm{C}$ ). The stomach was dissected, then smaller and smooth rectangular tissue pieces (approximately $1 \times 1.5 \mathrm{~cm}$ ) were carefully ablated from the mucosal fold part (rugae) of the organ, using a surgical scalper. Simulated gastric fluid pre-warmed in a $37^{\circ} \mathrm{C}$ water bath was used for modelling the wash-off process of the test microparticles from the mucosal surface.

The retention study was carried out firstly by spreading $0.02 \mathrm{~g}$ aliquot of fluorescent particles over one edge of ex vivo pre-rinsed mucosal surface of the tissue piece fixed on one end of a microscope slide. The microscope slide was fixed at an angle of $20^{\circ}$ to the ground to ensure the consistent flow of simulated gastric fluid through the microparticles, while the portable microscope was oriented perpendicularly to the tissue surface, pointing the objective lens in the direction of particles on the mucosal tissue. The UV torch was set to be sloped towards the tissue at $45^{\circ}$ angle and at a distance of $40 \mathrm{~mm}$. With this arrangement, the aim was to ensure that the UV light intensity provides an optimally exposed and threshold imaging of the fluorescent particles (distinguishing them from the background fluorescence). After placing the tissue into the incubator, SGF was 
allowed to drip through a needle onto the tissue surface using a syringe pump at $5 \mathrm{~mL} / \mathrm{min}$. This specific flow rate mimics the average in vivo gastric secretion rates reported for both fasted and active digestion periods (Versantvoort et al., 2004). These series of droplets were directed to fall from a height of $15 \mathrm{~mm}$ to exclude the needle from the microscope field of view, and $\sim \mathrm{mm}$ away from the mucoadhesive formulation to ensure efficient wash off. All the fluid passed through the mucosal tissue was simultaneously collected in a container. The tissue area of interest was captured using the camera of the microscope at specific time points after interrupting the washing process and the liquid was totally drained off for $2 \mathrm{~min}$. In order to capture the entire particle mass on the tissue, we used a 40× magnification on the microscope and a distance of around $15 \mathrm{~mm}$ between the objective lens and the tissue surface (particle mass) during the whole test. All the acquired images underwent the same light intensity correction and were analysed using ImageJ software to quantify the intensity of fluorescence after each wash. All these experiments were performed in triplicate for each formulation using an incubator at $37^{\circ} \mathrm{C}$ and under dark conditions.

251

252

253

254

255

256

257

258

259

260

261

262

Incubator

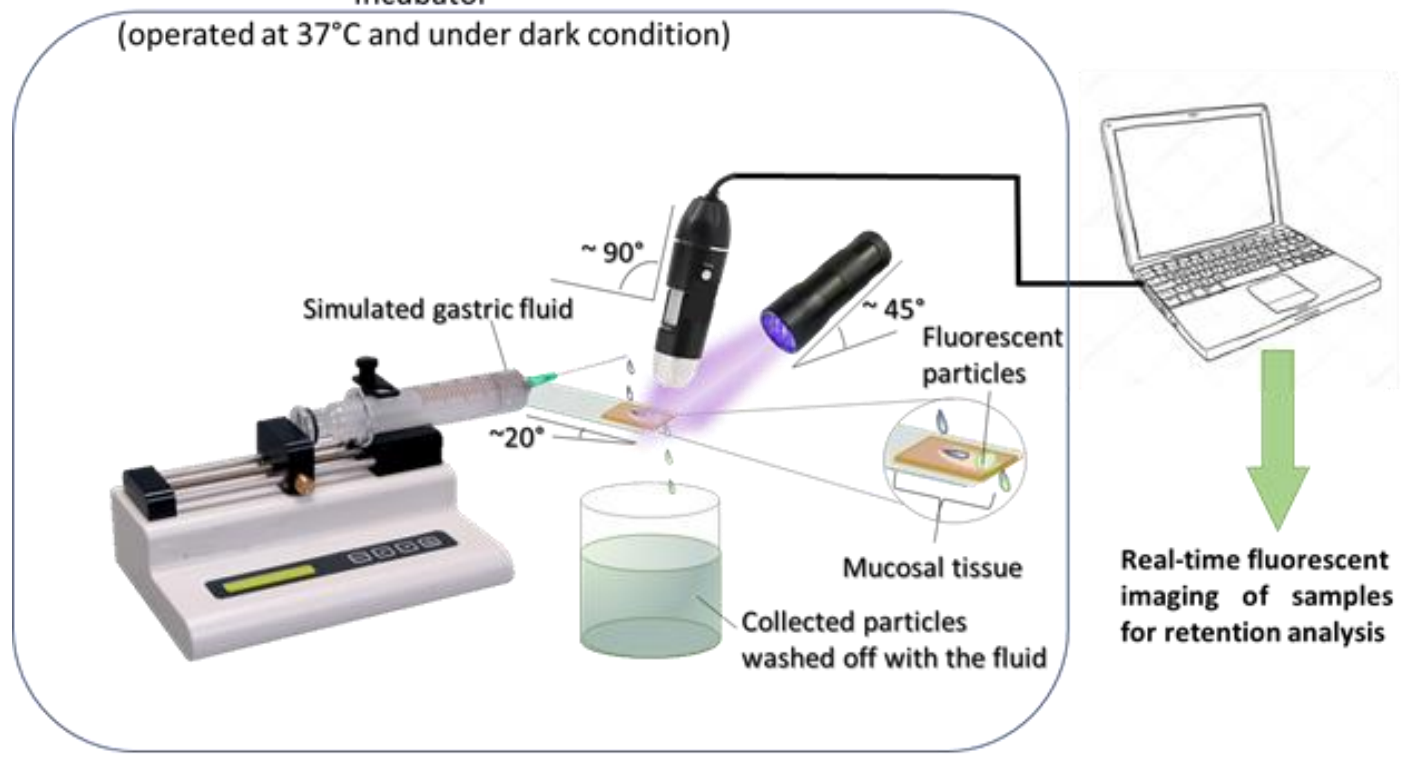

Fig. 2. Experimental set-up for the retention study of particles on gastric mucosa. The microscope, flashlight torch and microscopic slide were fixed at specified positions by using lab stands. Applied distance of objective lens - mucosal surface was $15 \mathrm{~mm}$, flashlight - mucosal surface was $40 \mathrm{~mm}$, needle tip - mucosal surface was $15 \mathrm{~mm}$, and fluid was flowing from $\sim 5 \mathrm{~mm}$ away to particles. Simulated gastric fluid was adjusted to flow at $5 \mathrm{~mL} / \mathrm{min}$.

\subsection{Statistical analysis}

Statistical analyses of all the results generated in this study were performed with GraphPad Prism software (version 8.0). One-way (or two-way where specified) analysis of variance (ANOVA) with a significance level of $\alpha=0.05$ was used to determine the statistical differences among any independent variables, whereas multiple comparisons of these ANOVA results were based on 
Tukey's post-hoc test. Final data were reported as the average value of three replicates, along with their corresponding standard error of the mean value.

\section{Results and discussion}

\subsection{Preparation and characterisation of microparticles}

Gel particles were successfully prepared using sodium alginate, resistant starch and chitosan as matrix-forming agents. Firstly, pure calcium alginate and a blend of alginate-starch particles were produced by electrospraying of $2 \%(\mathrm{w} / \mathrm{v})$ sodium alginate and $2 \%(\mathrm{w} / \mathrm{v}) / 2 \%(\mathrm{w} / \mathrm{v})$ alginate resistant starch solution, respectively, into $0.05 \mathrm{M} \mathrm{CaCl}_{2}$ solution. A third type of particles was generated by coating the alginate particles with chitosan. Additionally, pure chitosan particles were prepared by electrospraying $2 \%(\mathrm{w} / \mathrm{v}$ ) chitosan solution (in $0.1 \mathrm{M}$ acetic acid) into $2 \mathrm{M} \mathrm{NaOH}$ solution (these particles will be later used as a positive control to study mucoadhesive properties).

Fluorescence microscopy images of the particles prepared using different polymeric constituents are presented in Figure 3. These microscopic observations confirmed that the electrospraying process yielded spherically shaped particles. A chitosan layer was successfully formed on the alginate bead surfaces, with an average thickness of $18.5 \mu \mathrm{m}$; this was measured using the ImageJ analysis software. The laser light diffraction analysis revealed that alginate microparticles were produced with a wide size distribution ranging from 30 to $600 \mu \mathrm{m}$ (and span $=1.069$, indicating the width of the distribution) and with the most part (12.95\%) of the microparticles population measured at $310 \mu \mathrm{m}$. This wide size range can be caused by low viscosity sodium alginate solution applied for the microcapsule formation (Zaeim et al., 2017). Very similar size distribution (and range) of alginate microcapsules has also been generated with the emulsion-based formation technique (Dikit et al., 2015). The wide distribution shifted to a greater size range of $60-1300$ $\mu \mathrm{m}$ (and a width of span $=1.060$ ) when chitosan coating was applied on the alginate microparticles. In this case, the most frequent size $(12.39 \%$, similar to the alginate microcapsules without coating) detected in the whole microparticle distribution increased to $586 \mu \mathrm{m}$ (Figure 3). Based on the volume (or mass)-based mean diameter value ( $\mathrm{D}[4,3]$, derived from the center of the volume (or mass) distribution (Resch-Genger, 2008), the mean sizes of the whole particle population are estimated to be $309 \mu \mathrm{m}$ and $607 \mu \mathrm{m}$ for uncoated alginate and coated alginate particles, respectively. However, it should be noted that some swelling and thus size expansion could have occurred while the alginate microparticles were stirred in the chitosan solution for the coating process; this could be attributed to the acidic conditions of the chitosan solution ( $\mathrm{pH} 2-3$ ), similarly to our previous report (Cook et al., 2011). Furthermore, both particle size distribution curves as seen in the volume density plot showed that the resultant particle size was not evenly distributed in the population as they spread out more towards the larger size range. A bimodal distribution is seen especially for the uncoated microparticles.

Such small sized microcapsules prepared with the electrospraying method are needed when they are intended to be incorporated into food products, as large particles can negatively affect the 
sensory and textural characteristics (generating some undesirable grittiness feeling) of the certain food (Gbassi and Vandamme, 2012). If a post-drying (e.g. freeze- or spray-drying) step is applied the particle size can be further reduced, although, at the same time, this might result in a lower 305 bacteria-loading yield, aggregation and cracking of the capsule gel matrix (Dianawati et al., 2016; 306 Cook et al., 2012).

307 The morphology related results are in agreement with the images generated using Morphologi 4 308 system (Figure 4). All particles have spherical shape and uniform size distribution.

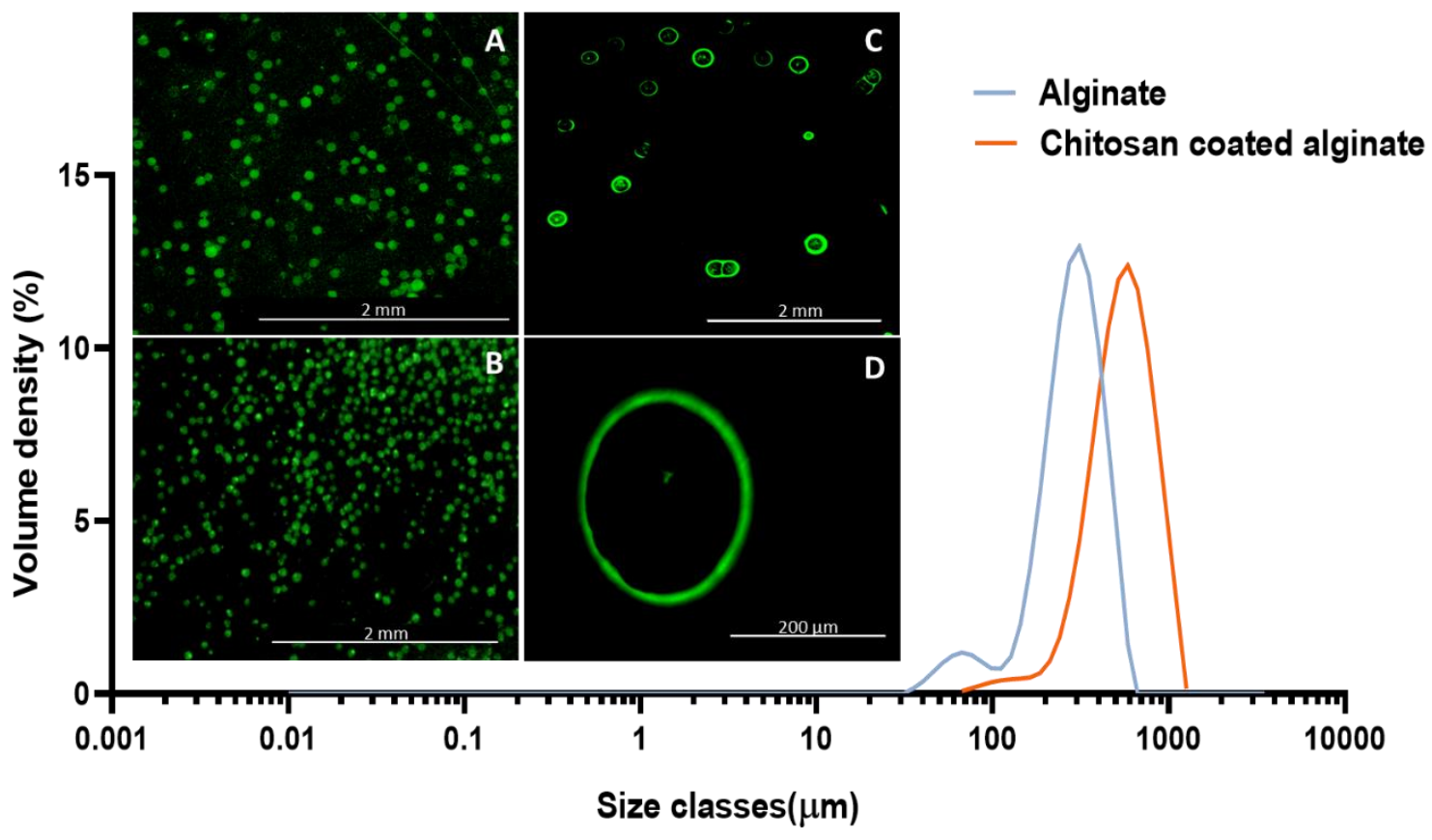

310 Fig. 3. Particle size distribution of alginate and chitosan-coated alginate microcapsules. Inserts 311 show fluorescent microscopy images representing alginate (A), alginate-starch (B) and chitosan 312 coating layer on alginate $(C$ and $D)$ particles. Applied magnifications (and scale bars): $0.8 \times(2 \mathrm{~mm})$ 313 for A, B, C and $8 \times(200 \mu \mathrm{m})$ for D images. 

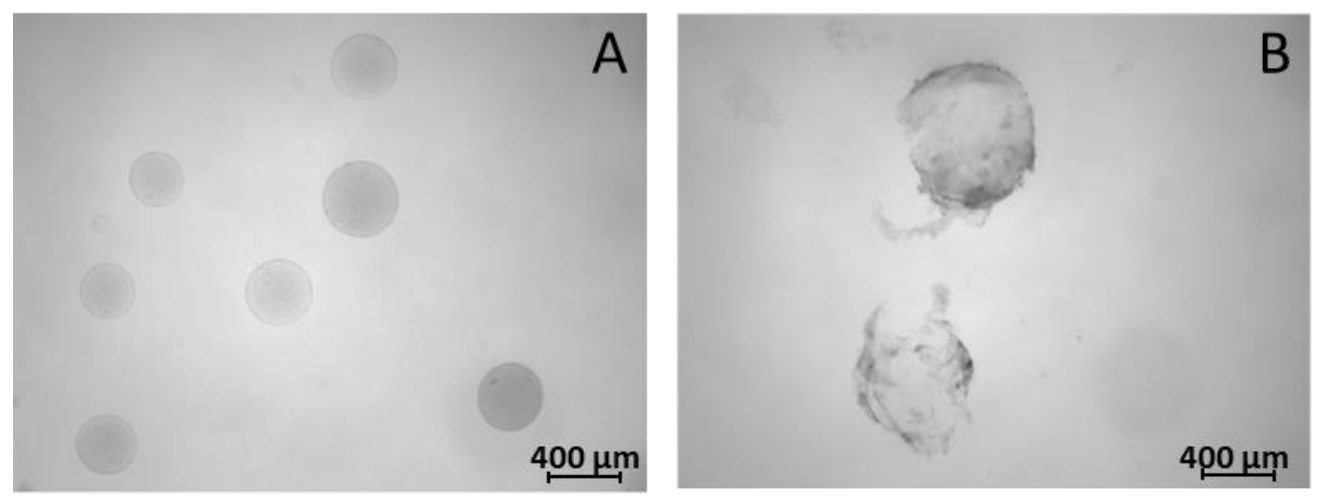

316

317

318

Fig. 4. Light microscopic images (scale bar $=400 \mu \mathrm{m}$ ) derived from Morphologi 4 automated particle image analyser for uncoated (A) and chitosan-coated alginate (B) particles.

\subsection{Bacterial survival yield after electrospray-based microencapsulation}

The initial cell count of $L$. plantarum prior to electrospraying was $8.94 \pm 0.12 \log \mathrm{CFU} / \mathrm{mL}$. Significant $(\mathrm{p}<0.05)$, but slightly less $(\sim 1.16 \log \mathrm{CFU} / \mathrm{mL})$ viable bacterial count could be detected in the microcapsules produced right after the electrosprayed-based microencapsulation. As can be seen in Figure 5, the incorporation of resistant starch did not affect the encapsulation yield (EY) of alginate-based microcapsules significantly. In particular, the microcapsules with alginate showed a decrease by $1.25 \log \mathrm{CFU} / \mathrm{mL}(\mathrm{EY}=5.6 \pm 1.7 \%)$, while alginate-starch particles resulted in viability loss of $1.06 \log \mathrm{CFU} / \mathrm{mL}(\mathrm{EY}=8.6 \pm 4.2 \%)$.

Gómez-Mascaraque et al. (2017), who encapsulated bacteria by electrospraying, achieved a greater bacterial survival of $32 \%$ for L. plantarum with inclusion of acidified gelatin-whey protein concentrate. However, they used coaxial approach and their EY was lower compared to our results. In the case of other microencapsulation techniques, the EY was generally found to be even higher on average with extrusion method (around $72 \%$ ) and with encapsulation in calcium alginate matrix [2 \% (w/v)] (Afzaal et al., 2019; Gul and Dervisoglu, 2017; Lotfipour et al., 2012). Moreover, bacterial survival of $47 \%$ was yielded after spray drying-based microencapsulation with mixed alginate and soy protein isolate (Hadzieva et al., 2017). However, a comparable result as with the present alginate-resistant starch microcapsules could be found for those formed with the emulsification method using calcium alginate (EY 10\%) (Gul and Dervisoglu, 2017). Here, the low yield especially for the alginate-entrapped bacteria resulted with electrospraying technique may be due to their potential sensitivity to the combined stress effect of the high voltage electric field, rapid water evaporation and high shearing force operated throughout the whole encapsulation process (Coghetto et al., 2016). 

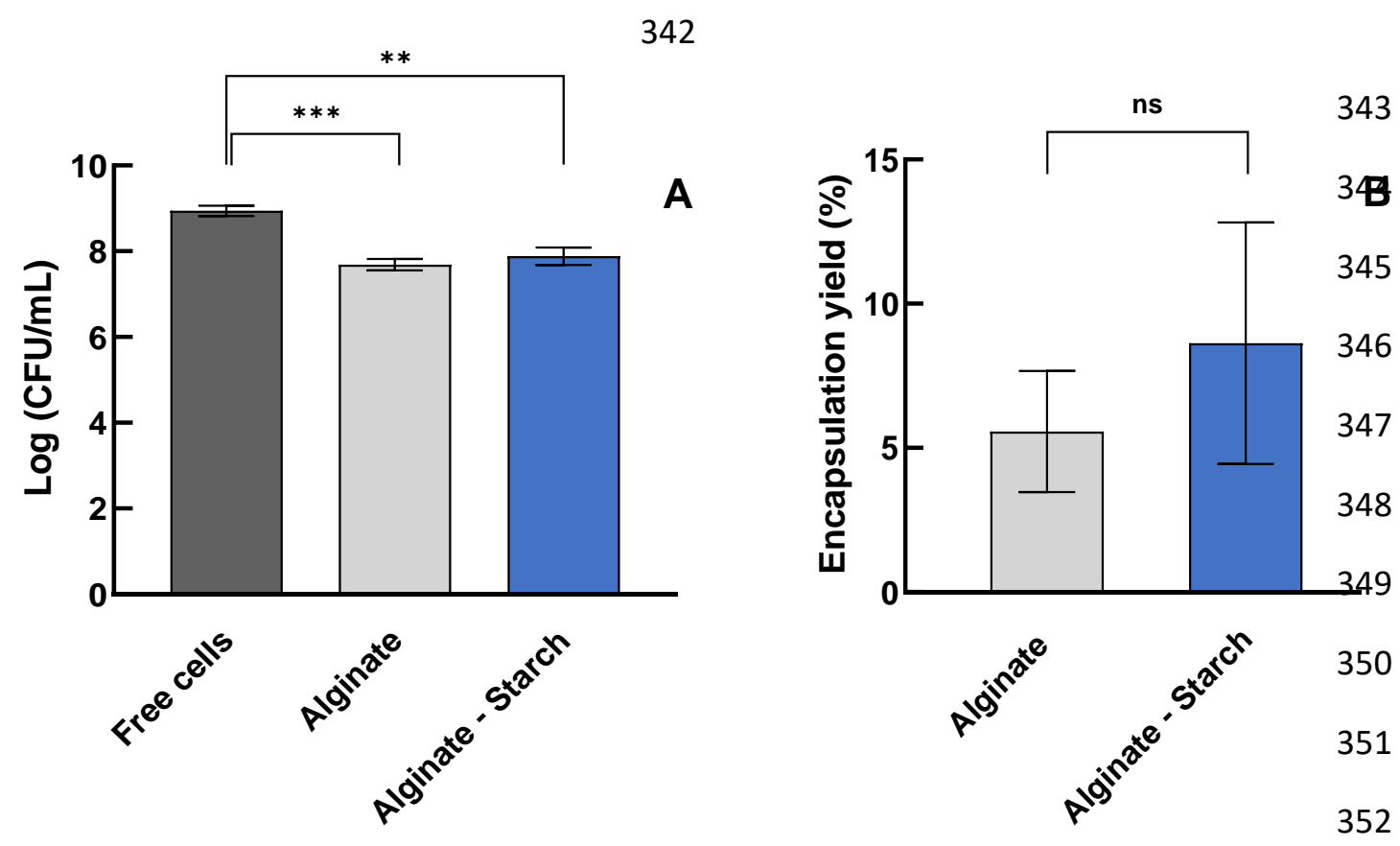

353

354

355

356

357

358

359

360

361

362

363

364

365

366

367

368

369

370

371

372

373

374

375

376

Fig. 5. Number of bacterial cells survived after the microencapsulation process by electrospraying procedure (A) and the calculated percentage yields (B) of survived cells encapsulated in alginate and alginate-starch microcapsules. Data are shown as mean \pm standard error of mean $(n=3)$. Significant differences are denoted by $* *(p<0.01)$ and 'ns' signifies no significant differences $(p$ $>0.05)$.

\subsection{Survival of free and microencapsulated bacteria exposed to simulated gastric condition}

The viability results of free and microencapsulated L. plantarum in simulated gastric fluid (SGF) [0.2\% (w/v) $\mathrm{NaCl}, \mathrm{pH} 2]$ over different exposure times are summarised in Figure 6. In view of these results, the microcapsules prepared by electrospraying provided significantly enhanced survival rates $(p<0.05)$ for bacteria within all formulations as no free cells were found even after $1 \mathrm{~h}$ of incubation, initiating from viable counts of $\log 8.14 \mathrm{CFU} / \mathrm{mL}$. Pure alginate microcapsules significantly underperformed in terms of bacterial protection, compared to other types of alginatebased microcapsules with either blending with resistant starch or chitosan coating $(\mathrm{p}<0.01)$. Electrosprayed alginate-starch and chitosan-coated alginate formulations retained the viability of L. plantarum with lower losses, i.e. by $0.76-2.14 \log \mathrm{CFU} / \mathrm{mL}$ and $0.49-3.68 \log \mathrm{CFU} / \mathrm{mL}$ after 1 $\mathrm{h}$ and $2 \mathrm{~h}$ in SGF compared to alginate microparticles, respectively.

Applying chitosan coating has been reported to improve the protection abilities of alginate-based microcapsules (Chávarri et al., 2010; Cook et al., 2011; Nualkaekul et al., 2012). This can arise from the decreased pore size of the calcium alginate hydrogels after the application of coating (Pestovsky and Martínez-Antonio, 2019), with which the contact of the bacteria with the gastric fluid could be limited. Interestingly, incorporating resistant starch into the alginate matrix resulted in a statistically similar protection with chitosan coating throughout the digestion process. The former one could be explained by the direct presence of the resistant starch component within the 
alginate matrix, which can serve as an energy and carbon source for the probiotic bacteria (Sultana et al., 2000; Zaman and Sarbini, 2015). Some previous studies have also reported enhanced bacteria protection in the microcapsules after exposure to gastric juice when resistant starch was blended with alginate but the microencapsulation itself was conducted with other, more common methods (Ashwar et al., 2018; Krasaekoopt et al., 2003; Muthukumarasamy et al., 2006). Zaeim et al. (2017), who likewise assessed electrospray-based microencapsulation of L. plantarum in alginate and consecutive coating with chitosan, showed similar viability reductions of around 2 and $3 \log \mathrm{CFU} / \mathrm{mL}$ after 1 and $2 \mathrm{~h}$ gastric ( $\mathrm{pH}$ 2.5) exposure, respectively. In another paper from the same authors, chitosan coated alginate microcapsules additionally incorporated with resistant starch, were reported to give a slightly weaker protection for L. plantarum than our resistant starchcontaining microcapsules during the $2 \mathrm{~h}$ simulated gastric digestion (Zaeim et al., 2019). No notable alginate gel matrix disintegration was observed for any formulations after the end of the gastric incubation, which can be associated with the fact that alginate exhibits an acid gel attribute at $\mathrm{pK}_{\mathrm{a}}$ below 3.5 (Nualkaekul et al., 2012; Onsoyen, 1999).

There has been an observation suggesting that an enhanced viability in a strong acidic condition (e.g., typical of gastric fluid) can be generally achieved with an increased microcapsule size/diameter (Chandramouli et al., 2004; Cook et al., 2012; Ding and Shah, 2009; Ferreira Grosso and Fávaro-Trindade, 2004; Liu et al., 2020; Muthukumarasamy et al., 2006). Our results were found only partially in agreement with this observation. As presented earlier, our microcapsules could be formed with a size range of $30-600 \mu \mathrm{m}$ by using the electrospraying technique, with which we experienced a cell viability reduction of more than $7 \log \mathrm{CFU} / \mathrm{mL}$ (to an undetectable level) in alginate microparticles after $2 \mathrm{~h}$ exposure to simulated gastric fluid. On the contrary, a much greater survival of $L$. plantarum in gastric condition $(\mathrm{pH} 1.5 ; 2 \mathrm{~h})$ was reported by Nualkaekul et al. (2012) with their larger sized alginate capsules ( $2.9 \mathrm{~mm})$. Likewise, a much better gastric protection of probiotics was also reported when alginate capsules with an average size of $2.37 \mathrm{~mm}$ were used (Muthukumarasamy et al., 2006). Similar result was also reported for resistant starch reinforced alginate by Sultana et al. (2000). However, in some cases, the viability of probiotics under the same gastric conditions could be maintained better when the cells were entrapped in microcapsules with a smaller or similar size range than our electrosprayed ones (Chun et al., 2014; Dikit et al., 2015; Muthukumarasamy et al., 2006). As these microcapsules were prepared under mild conditions, this may be due to the fact that the application of the electrostatic field during the microencapsulation process could further weaken the subsequent acidic stress tolerance of probiotics, possibly in combination with the effect of the small microcapsule size. 


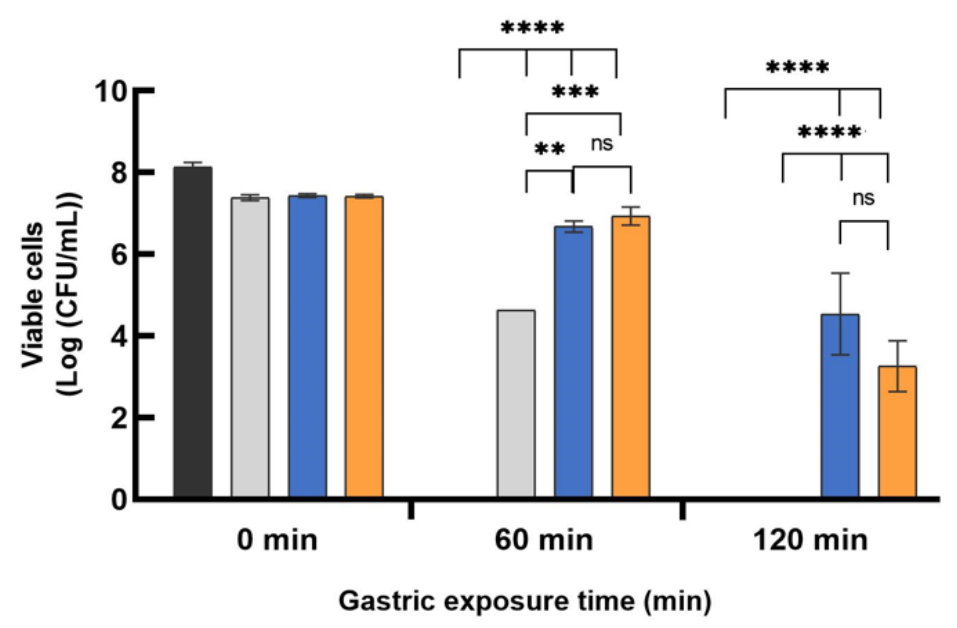

Alginate - Starch

$\square$ Chitosan-coated alginate

412 Fig. 6. Viable numbers $(\mathrm{CFU} / \mathrm{mL})$ of free and microencapsulated L. plantarum bacteria with alginate, alginate-starch and chitosan-coated alginate microcapsules over $2 \mathrm{~h}$ of exposure to simulated gastric fluid $[0.2 \%(\mathrm{w} / \mathrm{v}) \mathrm{NaCl}, \mathrm{pH} 2]$ at $37^{\circ} \mathrm{C}$. Significant p-values are denoted by $* *$ $(\mathrm{p}<0.01), * * *(\mathrm{p}<0.001), * * * *(\mathrm{p}<0.0001)$, and $\mathrm{ns}(\mathrm{p}>0.05)$ is for indicating non-significant differences, determined using two-way ANOVA with Tukey's multiple comparison post-hoc tests. Data are all shown as mean \pm standard error of mean $(n=3)$.

\subsection{Mucoadhesion study of microcapsules on gastric mucosa}

419

420

421

422

423

424

425

426

427

428

429

430

431

432

433

434

435

436

437

438

Aside from keeping an adequate bacterial survival rate, several studies have also highlighted the importance of mucosal retention of microcapsules within the gastrointestinal tract for appreciably longer time, in the context of designing effective delivery systems for probiotics (Alli et al., 2011; Cook et al., 2012; van Tassell and Miller, 2011). For instance, retention on gastric epithelium may potentially improve the chance of some probiotics to curb gastric ulcers and gastric cancer diseases induced by Helicobacter pylori and to contribute gastric mucosal barrier protection. Furthermore, it is also reported that gastric mucus itself can provide an additional potential protective function for gastric survival of probiotics (Butel, 2014; Khoder et al., 2016; Koga et al., 2019; Singh et al., 2012). Accordingly, the mucoadhesive properties of unloaded alginate, alginate-starch and chitosan-coated alginate microparticles were evaluated using an in vitro fluorescence imagingbased flow-through test on ex vivo porcine gastric epithelial mucosa, following the protocol described previously by the Khutoryanskiy group (Cook et al., 2018; Kaldybekov et al., 2018; Porfiryeva et al., 2019). As some recent reports also suggested the potential utilisation of a lowcost commercial USB microscope in different imaging-related assays (Bracker and Stender, 2019; Tortajada-genaro et al., 2019), here, we attempted to adapt this device for imaging the samples in the present mucoadhesion study, with assessing the usability of that as an alternative imaging tool for this study.

The retention on the mucosa was observed based on the detected intensity of the fluorescent particles labelled with the agents mentioned in Section 2.5. To ensure the excitation of the fluorophores a portable UV LED flashlight torch was applied. SGF with pH 2 was used to wash 
the particles off the mucosal surface. To avoid the leakage of fluorescent tracers, both alginate and alginate-starch particles were labelled with the greater molecular weight FITC-dextran instead of sodium fluorescein. A positive control experiment was also undertaken with pure chitosan particles.

Figure 7 presents the retention profiles observed for different microparticles on gastric mucosa through the series of captured fluorescent photomicrographs. It should be noted that the lowest available magnification of $40 \times$ was needed for evaluating the whole particle mass. According to the analysis using Image $J$ software, it is confirmed that every type of microcapsules could remain to some extent on the gastric mucosa even up to $2 \mathrm{~h}$. Among them, chitosan-coated alginate particles exhibited excellent retention ability, comparable to that of pure chitosan control ( $\mathrm{p}>$ $0.05)$. For this formulation, around $62 \%$ and $32 \%$ of remaining fluorescence intensity could still be observed after $60 \mathrm{~min}$ and $120 \mathrm{~min}$ of washing, respectively. On the other hand, more rapid removal was observed in case of pure alginate, especially over the last $50 \mathrm{~min}$ of the $2 \mathrm{~h}$ experiment. Slightly weaker retention of alginate-starch particles was observed compared to pure alginate microcapsules. Improved mucoadhesion, however, can be feasible via some chemical modifications or addition of specific functional groups (Jelkmann et al., 2019; Kaldybekov et al., 2018). It should be noted that these weak gastric-mucoadhesive characteristics can be preferable if the primary site of therapeutic action of the particular probiotic strain is the intestinal tract. The exemplary series of fluorescent images representing the retention rate of each examined formulation are shown in Figure 8.

It is well known that chitosan exhibits strong mucoadhesive properties due to its cationic nature (Khutoryanskiy, 2011). Therefore, we have used chitosan particles as a positive control in these experiments. As it was expected, these particles show the greatest retention on mucosal surfaces in our experiments. The alginate capsules, coated with chitosan, exhibited poorer retention than pure chitosan particles but better mucoadhesive properties than uncoated alginate capsules. This is explained by the presence of chitosan on their surface. Starch is a non-ionic polysaccharide and it is expected to exhibit poor mucoadhesive properties (Khutoryanskiy, 2011). Indeed, an addition of starch to alginate makes the microcapsules less retentive on the mucosa. 


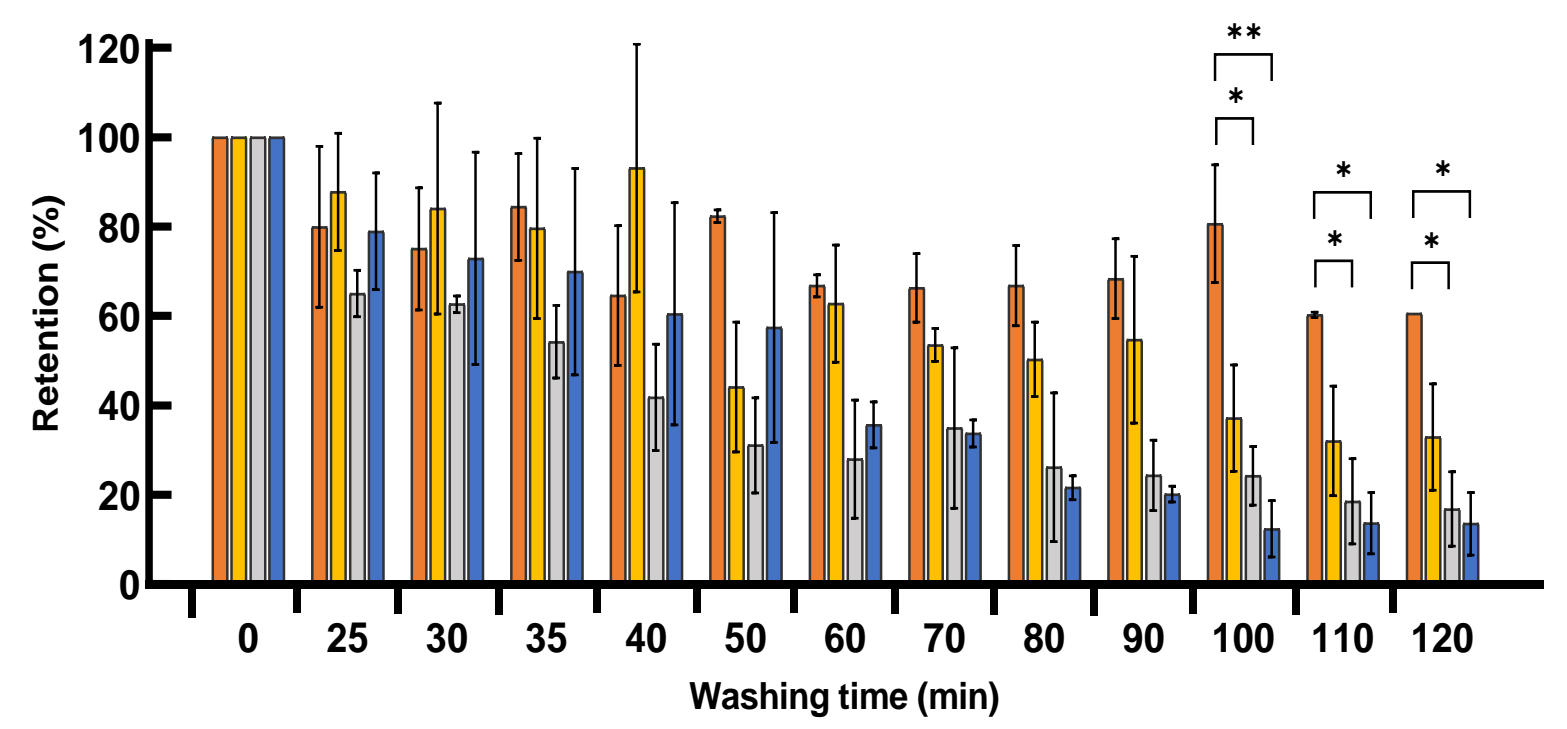

468 Fig. 7. In vitro retention profiles of each microcapsule variation on ex vivo porcine gastric mucosa 469 over $2 \mathrm{~h}$ of washing process with simulated gastric fluid $(0.2 \%(\mathrm{w} / \mathrm{v}) \mathrm{NaCl}, \mathrm{pH} 2)$ at $37^{\circ} \mathrm{C}$. 470 Statistical differences are denoted by $*(\mathrm{p}<0.05)$ and $* *(\mathrm{p}<0.01)$. Values are represented as 471 mean \pm standard error of mean $(n=3)$.

472

473 


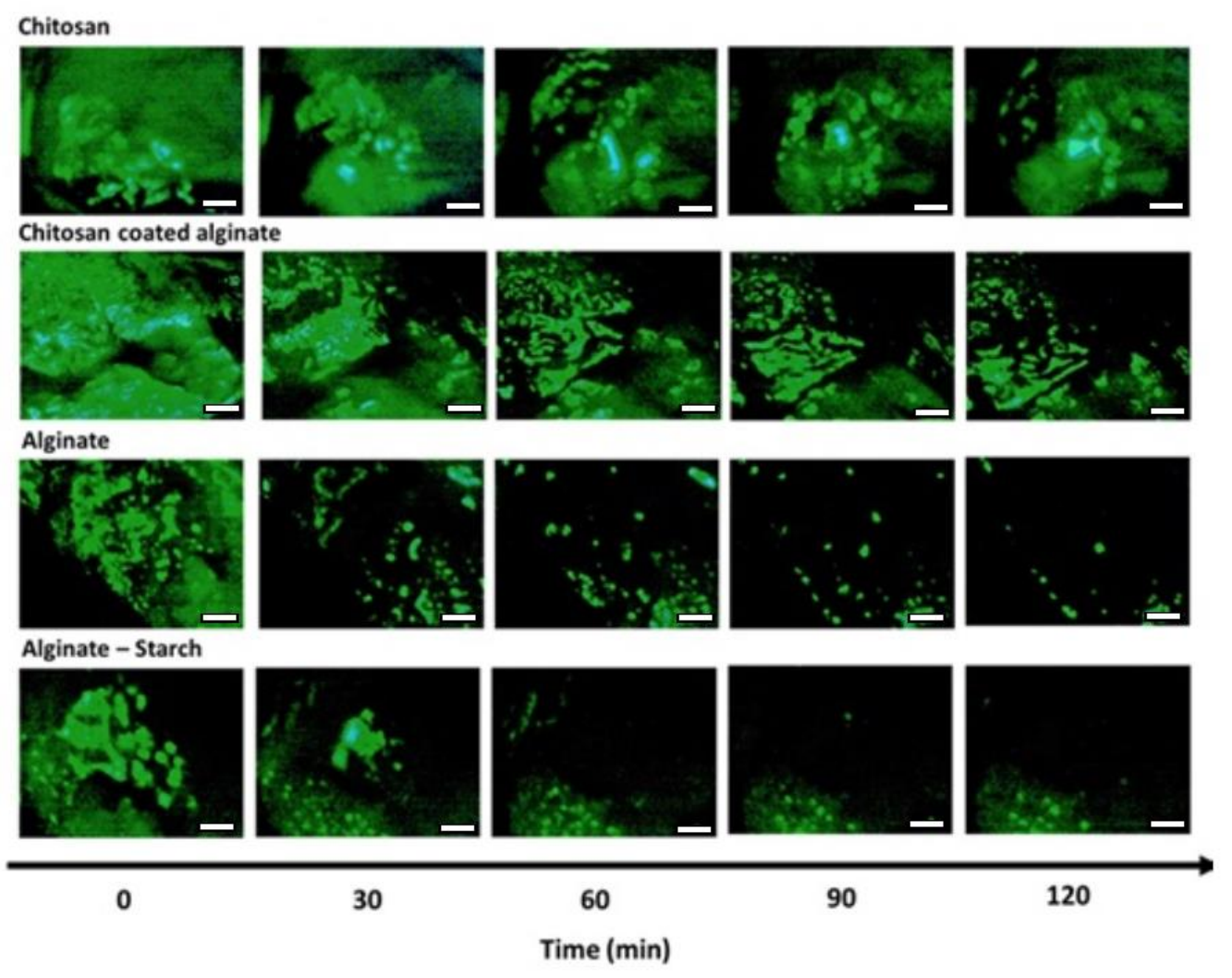

474

475

476

477

478

479

480

481

482

483

484

485

486

487

488

489

490

491

492

493

Fig. 8. Example fluorescence images showing retention of each variation of microcapsules on porcine gastric mucosa after the indicated time of washing with simulated gastric fluid $(0.2 \%$ (w/v) $\mathrm{NaCl}, \mathrm{pH} 2$ ). Scale bar is $1000 \mu \mathrm{m}$.

Overall, the experiments with a portable digital USB microscope and UV light torch indicate the suitability of this low cost approach for performing fluorescence flow-through test to evaluate mucoadhesive properties of microcapsules. The use of this experimental setup can offer a number of advantages over the traditional fluorescent microscopy method, including the possibility for real-time imaging and detection capability in micro-scale resolution, video recording capability, user-friendliness, portability, increased affordability and availability of analysis.

\section{Conclusions}

In this study, alginate, blend of alginate-resistant starch and chitosan-coated alginate-based microcapsules were successfully prepared and loaded with Lactobacillus plantarum probiotic bacteria using the electrospray technique. Each type of microcapsules was characterized using laser light diffraction, encapsulation yield of survived bacteria, fluorescent microscopy, in vitro gastric digestion and in vitro gastro-retention analysis. The electrospraying resulted in the production of spherically shaped microcapsules with a size range of 30-600 $\mu \mathrm{m}$ (and a volumebased mean diameter of $309 \mu \mathrm{m}$ ), which increased to $60-1300 \mu \mathrm{m}$ (and a volume-based mean 
diameter of $607 \mu \mathrm{m}$ ) with chitosan coating. No statistically significant difference was found in the encapsulation yield of viable cells between alginate and alginate-starch formulations, but some significant losses in bacteria viability occurred following the encapsulation process. Microcapsules with alginate-starch matrix provided one of the most effective viability protection for bacteria in simulated gastric conditions (for $2 \mathrm{~h}$ ) with a viable loss of $2.14 \log \mathrm{CFU} / \mathrm{mL}$, comparable to that of chitosan coated alginate particles. On the contrary, this formulation exhibited weak retention on gastric mucosa compared to particles with alginate only and especially alginate-chitosan microparticles. This research demonstrated that electrospraying could be successfully used for preparation of microcapsules with viable probiotic bacteria. These microcapsules provide adequate protection to these bacteria against harsh environment in the stomach. Although a high bacteria loading capacity ( $\sim 8 \log \mathrm{CFU} / \mathrm{mL}$ ) was achieved with this technology, further investigations may be needed with regard to their storage stability within these microcapsules.

Additionally, it was demonstrated that a low-cost handheld consumer USB microscope, under some specific conditions, can be used as an alternative device to perform imaging of fluorescent samples involved in the retention test for mucoadhesion analysis. Potentially this approach could be used in laboratories, where researchers do not have access to expensive fluorescence microscopes. This gives an opportunity to a wider range of research groups to use fluorescence flow-through assay to evaluate mucoadhesive properties and retention of formulations ex vivo.

\section{Acknowledgement}

The European Union's Erasmus+ programme is thanked for funding the stay of L. P. Ta at the University of Reading. Malvern Panalytical is also acknowledged for helping with particle size distribution measurements. Furthermore, we are grateful to Dr. Afroditi Chatzifragkou and also Robert Shackleford, along with the other members of technician staff at the Department of Food and Nutritional Science for providing help in the microbiological part of this study. Finally, L. P. $\mathrm{Ta}$ is also grateful for all the help from the members of the Khutoryanskiy research group, among others, Roman V. Moiseev, Jamila H. Al Mahrooqi and Sam Aspinall. 


\section{References}

Afzaal, M., Khan, A.U., Saeed, F., Ahmed, A., Ahmad, M.H., Maan, A.A., Tufail, T., Anjum, F.M., Hussain, S., 2019. Functional exploration of free and encapsulated probiotic bacteria in yogurt and simulated gastrointestinal conditions. Food Sci. Nutr. 7, 3931-3940. https://doi.org/10.1002/fsn3.1254

Alli, S.M.A., Ali, S.M.A., Samanta, A., 2011. Development and evaluation of intestinal targeted mucoadhesive microspheres of Bacillus coagulans. Drug Dev. Ind. Pharm. 37, 1329-1338. https://doi.org/10.3109/03639045.2011.572889

Ashwar, B.A., Gani, Asir, Gani, Adil, Shah, A., Masoodi, F.A., 2018. Production of RS4 from rice starch and its utilization as an encapsulating agent for targeted delivery of probiotics. Food Chem. 239, 287-294. https://doi.org/10.1016/j.foodchem.2017.06.110

ASTM Standard E799-03, 2015. Standard practice for determining data criteria and processing for liquid drop size analysis. ASTM Int. West Conshohocken, PA 03, 1-5. https://doi.org/10.1520/E0799$03 \mathrm{R} 09.2$

Bhushani, A., Harish, U., Anandharamakrishnan, C., 2017. Nanodelivery Of Nutrients For Improved Bioavailability, in: Grumezescu, A.M. (Ed.), Nutrient Delivery. Elsevier, pp. 369-411. https://doi.org/10.1016/B978-0-12-804304-2.00010-X

Bracker, R., Stender, A.S., 2019. Efficacy of USB microscopes for imaging forensic materials. Forensic Sci. Int. 304,109961. https://doi.org/10.1016/j.forsciint.2019.109961

Butel, M.-J., 2014. Probiotics, gut microbiota and health. Médecine et Maladies Infectieuses, 44, 1-8. https://doi.org/10.1016/j.medmal.2013.10.002

Chandramouli, V., Kailasapathy, K., Peiris, P., Jones, M., 2004. An improved method of microencapsulation and its evaluation to protect Lactobacillus spp. in simulated gastric conditions. J. Microbiol. Methods 56, 27-35. https://doi.org/10.1016/j.mimet.2003.09.002

Chavarri, M., Maranon, I., Carmen, M., 2012. Encapsulation Technology to Protect Probiotic Bacteria, in: Probiotics. InTech, pp. 501-540. https://doi.org/10.5772/50046

Chen, M.J., Chen, K.N., 2007. Applications of Probiotic Encapsulation in Dairy Products, in: Lakkis, J.M. (Ed.), Encapsulation and Controlled Release Technologies in Food Systems. Wiley Blackwell, pp. 83-112. https://doi.org/10.1002/9780470277881.ch4

Chun, H., Kim, C.H., Cho, Y.H., 2014. Microencapsulation of Lactobacillus plantarum DKL 109 using external ionic gelation method. Korean J. Food Sci. Anim. Resour. 34, 692-699. https://doi.org/10.5851/kosfa.2014.34.5.692

Coghetto, C.C., Brinques, G.B., Siqueira, N.M., Pletsch, J., Soares, R.M.D., Ayub, M.A.Z., 2016. Electrospraying microencapsulation of Lactobacillus plantarum enhances cell viability under refrigeration storage and simulated gastric and intestinal fluids. J. Funct. Foods 24, 316-326. https://doi.org/10.1016/j.jff.2016.03.036

Cook, M.T., Tzortzis, G., Charalampopoulos, D., Khutoryanskiy, V. V., 2012. Microencapsulation of probiotics for gastrointestinal delivery. J. Control. Release 162, 56-67. 
https://doi.org/10.1016/j.jconrel.2012.06.003

Cook, M.T., Tzortzis, G., Charalampopoulos, D., Khutoryanskiy, V. V., 2011. Production and evaluation of dry alginate-chitosan microcapsules as an enteric delivery vehicle for probiotic bacteria. Biomacromolecules 12, 2834-2840. https://doi.org/10.1021/bm200576h

Cook, S.L., Woods, S., Methven, L., Parker, J.K., Khutoryanskiy, V. V., 2018. Mucoadhesive polysaccharides modulate sodium retention, release and taste perception. Food Chem. 240, 482-489. https://doi.org/10.1016/j.foodchem.2017.07.134

Corona-Hernandez, R.I., Álvarez-Parrilla, E., Lizardi-Mendoza, J., Islas-Rubio, A.R., de la Rosa, L.A., Wall-Medrano, A., 2013. Structural stability and viability of microencapsulated probiotic bacteria: A review. Compr. Rev. Food Sci. Food Saf. 12, 614-628. https://doi.org/10.1111/1541-4337.12030

Davani-Davari, D., Negahdaripour, M., Karimzadeh, I., Seifan, M., Mohkam, M., Masoumi, S., Berenjian, A., Ghasemi, Y., 2019. Prebiotics: Definition, Types, Sources, Mechanisms, and Clinical Applications. Foods 8, 92. https://doi.org/10.3390/foods8030092

Das, A., Ray, S., Raychaudhuri, U., Chakraborty, R., 2014. Microencapsulation of probiotic bacteria and its potential application in food technology. Int. J. Agric. Environ. Biotechnol. 7, 47. https://doi.org/10.5958/j.2230-732x.7.1.007

Dianawati, D., Mishra, V., Shah, N.P., 2016. Survival of microencapsulated probiotic bacteria after processing and during storage: A Review. Crit. Rev. Food Sci. Nutr. 56, 1685-1716. https://doi.org/10.1080/10408398.2013.798779

Dikit, P., H-Kittikun, A., Maneerat, S., 2015. Survival of encapsulated potentially probiotic Lactobacillus plantarum D6SM3 with bioemulsifier derived from spent yeast in simulated gastrointestinal conditions. Songklanakarin J. Sci. Technol. 37, 425-432.

Ding, W.K., Shah, N.P., 2009. Effect of homogenization techniques on reducing the size of microcapsules and the survival of probiotic bacteria therein. J. Food Sci. 74, M231-M236. https://doi.org/10.1111/j.1750-3841.2009.01195.x

Dodoo, C.C., Wang, J., Basit, A.W., Stapleton, P., Gaisford, S., 2017. Targeted delivery of probiotics to enhance gastrointestinal stability and intestinal colonisation. Int. J. Pharm. 530, 224-229. https://doi.org/10.1016/j.ijpharm.2017.07.068

El-Abd, M.M., Abdelhamid, M., El-Sayed, H., A.El-Metwaly, H., El-Demerdash, M.E., Mohamed, Z., 2018. Viability of microencapsulated probiotics combined with plant extracts in fermented camel milk under simulated gastrointestinal conditions. Middle East J. Appl. Sci. 08, 837-850.

FAO/WHO, 2001. Health and nutritional properties of probiotics in food including powder milk with live lactic acid bacteria - Joint FAO/WHO Expert Consultation [WWW Document]. Heal. Nutr. Prop. Guidel. Eval. https://doi.org/10.1109/ISI.2013.6578843

Gbassi, G.K., Vandamme, T., 2012. Probiotic encapsulation technology: From microencapsulation to release into the gut. Pharmaceutics 4, 149-163. https://doi.org/10.3390/pharmaceutics4010149

Gombotz, W.R., Wee, S.F., 2012. Protein release from alginate matrices. Adv. Drug Deliv. Rev. 64, 194- 
610

611

612

613

Gómez-Mascaraque, L.G., Ambrosio-Martín, J., Perez-Masiá, R., Lopez-Rubio, A., 2017. Impact of acetic acid on the survival of L. plantarum upon microencapsulation by coaxial electrospraying. . https://doi.org/10.1155/2017/4698079

Ferreira Grosso, C.R., Fávaro-Trindade, C.S., 2004. Stability of free and immobilized Lactobacillus acidophilus and Bifidobacterium lactis in acidified milk and of immobilized B. lactis in yoghurt. Brazilian J. Microbiol. 35, 151-156. https://doi.org/10.1590/s1517-83822004000100025

Fredua-Agyeman, M., Gaisford, S., 2015. Comparative survival of commercial probiotic formulations: Tests in biorelevant gastric fluids and real-time measurements using microcalorimetry. Benef. Microbes 6, 141-151. https://doi.org/10.3920/BM2014.0051

Gul, O., Dervisoglu, M., 2017. Application of multicriteria decision technique to determine optimum sodium alginate concentration for microencapsulation of Lactobacillus casei Shirota by extrusion and emulsification. J. Food Process Eng. 40, e12481. https://doi.org/10.1111/jfpe.12481

Hadzieva, J., Mladenovska, K., Simonoska Crcarevska, M., Glavaš Dodov, M., Dimchevska, S., Geškovski, N., Grozdanov, A., Popovski, E., Petruševski, G., Chachorovska, M., Petreska Ivanovska, T., Petruševska-Tozi, L., Ugarkovic, S., Goracinova, K., 2017. Lactobacillus casei loaded soy protein-alginate microparticles prepared by spray-drying. Food Technol. Biotechnol. 55, 173-186. https://doi.org/10.17113/ftb.55.02.17.4991

Heidebach, T., Först, P., Kulozik, U., 2012. Microencapsulation of Probiotic Cells for Food Applications. Crit. Rev. Food Sci. Nutr. 52, 291-311. https://doi.org/10.1080/10408398.2010.499801

Jelkmann, M., Leichner, C., Menzel, C., Kreb, V., Bernkop-Schnürch, A., 2019. Cationic starch derivatives as mucoadhesive and soluble excipients in drug delivery. Int. J. Pharm. 570, 118664. https://doi.org/10.1016/j.ijpharm.2019.118664

Kaldybekov, D.B., Tonglairoum, P., Opanasopit, P., Khutoryanskiy, V. V., 2018. Mucoadhesive maleimide-functionalised liposomes for drug delivery to urinary bladder. Eur. J. Pharm. Sci. 111, 83-90. http://dx.doi.org/10.1016/j.ejps.2017.09.039

Khoder, G., Al-Menhali, A.A., Al-Yassir, F., Karam, S.M., 2016. Potential role of probiotics in the management of gastric ulcer. Exp. Ther. Med. 12, 3-17. https://doi.org/10.3892/etm.2016.3293

Khutoryanskiy, V. V., 2011. Advances in mucoadhesion and mucoadhesive polymers. Macromol. Biosci. 11, 748-64. https://doi.org/10.1002/mabi.201000388

Khutoryanskiy, V. V., 2014. Mucoadhesive Materials and Drug Delivery Systems, John Wiley \& Sons, Ltd, Chichester, United Kingdom. https://doi.org/10.1002/9781118794203

Koga, Y., Ohtsu, T., Kimura, K., Asami, Y., 2019. Probiotic L. gasseri strain (LG21) for the upper gastrointestinal tract acting through improvement of indigenous microbiota. BMJ Open Gastroenterol. 6, e000314. https://doi.org/10.1136/bmjgast-2019-000314

Krasaekoopt, W., Bhandari, B., Deeth, H., 2003. Evaluation of encapsulation techniques of probiotics for yoghurt. Int. Dairy J. 13, 3-13. https://doi.org/10.1016/S0958-6946(02)00155-3

Krasaekoopt, W., Watcharapoka, S., 2014. Effect of addition of inulin and galactooligosaccharide on the survival of microencapsulated probiotics in alginate beads coated with chitosan in simulated 
digestive system, yogurt and fruit juice. LWT - Food Sci. Technol. 57, 761-766. https://doi.org/10.1016/j.lwt.2014.01.037

Librán, C.M., Castro, S., Lagaron, J.M., 2017. Encapsulation by electrospray coating atomization of probiotic strains. Innov. Food Sci. Emerg. Technol. 39, 216-222. https://doi.org/10.1016/j.ifset.2016.12.013

Liu, H., Xie, M., Nie, S., 2020. Recent trends and applications of polysaccharides for microencapsulation of probiotics. Food Front. 1, 45-59. https://doi.org/10.1002/fft2.11

Lotfipour, F., Mirzaeei, S., Maghsoodi, M., 2012. Evaluation of the effect of $\mathrm{CaCl}_{2}$ and alginate concentrations and hardening time on the characteristics of Lactobacillus acidophilus loaded alginate beads using response surface analysis. Adv. Pharm. Bull. 2, 71-78. https://doi.org/10.5681/apb.2012.010

Martín, M.J., Lara-Villoslada, F., Ruiz, M.A., Morales, M.E., 2015. Microencapsulation of bacteria: A review of different technologies and their impact on the probiotic effects. Innov. Food Sci. Emerg. Technol. 27, 15-25. https://doi.org/10.1016/j.ifset.2014.09.010

Martin, M.J., Lara-Villoslada, F., Ruiz, M.A., Morales, M.E., 2013. Effect of unmodified starch on viability of alginate-encapsulated Lactobacillus fermentum CECT5716. LWT - Food Sci. Technol. 53, 480-486. https://doi.org/10.1016/j.1wt.2013.03.019

Miles, A.A., Misra, S.S., Irwin, J.O., 1938. The estimation of the bactericidal power of the blood. J. Hyg. (Lond). 38, 732-749. https://doi.org/10.1017/S002217240001158X

Minelli, E.B., Benini, A., 2008. Relationship between number of bacteria and their probiotic effects. Microb. Ecol. Health Dis. 20, 180-183. https://doi.org/10.1080/08910600802408095

Muthukumarasamy, P., Allan-Wojtas, P., Holley, R.A., 2006. Stability of Lactobacillus reuteri in different types of microcapsules. J. Food Sci. 71, 20-24. https://doi.org/10.1111/j.13652621.2006.tb12395.x

Nazir, Y., Hussain, S.A., Abdul Hamid, A., Song, Y., 2018. Probiotics and their potential preventive and therapeutic role for cancer, high serum cholesterol, and allergic and hiv diseases. Biomed Res. Int. 2018, 1-17. https://doi.org/10.1155/2018/3428437

Nualkaekul, S., Lenton, D., Cook, M.T., Khutoryanskiy, V. V., Charalampopoulos, D., 2012. Chitosan coated alginate beads for the survival of microencapsulated Lactobacillus plantarum in pomegranate juice. Carbohydr. Polym. 90, 1281-1287. https://doi.org/10.1016/j.carbpol.2012.06.073

Onsoyen, E., 1992. Alginates, in: Imeson, A. (Ed.), Thickening and Gelling Agents for Food. Springer, Boston, MA, pp. 1-24. https://doi.org/10.1007/978-1-4615-3552-2_1

Pestovsky, Y.S., Martínez-Antonio, A., 2019. The synthesis of alginate microparticles and nanoparticles. Drug Des. Intellect. Prop. Int. J. 3, 293-327. https://doi.org/10.32474/DDIPIJ.2018.03.000155

Porfiryeva, N.N., Nasibullin, S.F., Abdullina, S.G., Tukhbatullina, I.K., Moustafine, R.I., Khutoryanskiy, V. V., 2019. Acrylated Eudragit ${ }^{\circledR}$ E PO as a novel polymeric excipient with enhanced mucoadhesive properties for application in nasal drug delivery. Int. J. Pharm. 562, 241-248. 
Resch-Genger, U., 2008. Standardization and Quality Assurance in Fluorescence Measurements II, Standardization and Quality Assurance in Fluorescence Measurements II, Springer Series on Fluorescence. Springer Berlin Heidelberg, Berlin, Heidelberg. https://doi.org/10.1007/978-3-540-70571-0

Sabikhi, L., Suthar, B., Thompkinson, D., 2011. Co-encapsulation with inulin to improve the survival of probiotic Lactobacillus acidophilus NCDC15 for synbiotic food applications. Milchwissenschaft 66, $18-22$.

Samedi, L., Charles, A.L., 2019. Viability of 4 probiotic bacteria microencapsulated with arrowroot starch in the simulated gastrointestinal tract (GIT) and yoghurt. Foods 8,175. https://doi.org/10.3390/foods8050175

Singh, P.K., Deol, P.K., Kaur, I.P., 2012. Entrapment of Lactobacillus acidophilus into alginate beads for the effective treatment of cold restraint stress induced gastric ulcer. Food Funct. 3, 83-90. https://doi.org/10.1039/C1FO10100E

Smidsrød, O., Skjåk-Bræk, G., 1990. Alginate as immobilization matrix for cells. Trends Biotechnol. https://doi.org/10.1016/0167-7799(90)90139-O

Solanki, H.K., Pawar, D.D., Shah, D.A., Prajapati, V.D., Jani, G.K., Mulla, A.M., Thakar, P.M., 2013. Development of microencapsulation delivery system for long-term preservation of probiotics as biotherapeutics agent. Biomed Res. Int. 2013. https://doi.org/10.1155/2013/620719

Sultana, K., Godward, G., Reynolds, N., Arumugaswamy, R., Peiris, P., Kailasapathy, K., 2000. Encapsulation of probiotic bacteria with alginate-starch and evaluation of survival in simulated gastrointestinal conditions and in yoghurt. Int. J. Food Microbiol. 62, 47-55. https://doi.org/10.1016/S0168-1605(00)00380-9

Tortajada-genaro, L.A., Seiti, E., Maquieira, Á., 2019. Talanta Consumer electronics devices for DNA genotyping based on loop-mediated isothermal amplification and array hybridisation. Talanta 198, 424-431. https://doi.org/10.1016/j.talanta.2019.01.124

van Tassell, M.L., Miller, M.J., 2011. Lactobacillus adhesion to mucus. Nutrients 3, 613-636. https://doi.org/10.3390/nu3050613

Versantvoort, C., Kamp, E. van de, Rompelberg, C., 2004. Development and applicability of an in vitro model in assessing the bioaccessibility of contaminants from food. RIVM Rep. 320102002 .

Wang, J., Jansen, J.A., Yang, F., 2019. Electrospraying: Possibilities and challenges of engineering carriers for biomedical applications-A Mini Review. Front. Chem. 7, 258. https://doi.org/10.3389/fchem.2019.00258

Yao, M., Xie, J., Du, H., McClements, D.J., Xiao, H., Li, L., 2020. Progress in microencapsulation of probiotics: A review. Compr. Rev. Food Sci. Food Saf. 19, 857-874. https://doi.org/10.1111/1541$\underline{4337.12532}$

Zaeim, D., Sarabi-Jamab, M., Ghorani, B., Kadkhodaee, R., Tromp, R.H., 2017. Electrospray assisted fabrication of hydrogel microcapsules by single- and double-stage procedures for encapsulation of probiotics. Food Bioprod. Process. 102, 250-259. https://doi.org/10.1016/j.fbp.2017.01.004 
722 Zaeim, D., Sarabi-Jamab, M., Ghorani, B., Kadkhodaee, R., Tromp, R.H., 2018. Electrospray-assisted 723 drying of live probiotics in acacia gum microparticles matrix. Carbohydr. Polym. 183, 183-191. 724 https://doi.org/10.1016/j.carbpol.2017.12.001

725 Zaeim, D., Sarabi-Jamab, M., Ghorani, B., Kadkhodaee, R., 2019. Double layer co-encapsulation of 726

727 probiotics and prebiotics by electro-hydrodynamic atomization. Lwt 110, 102-109. https://doi.org/10.1016/j.lwt.2019.04.040

728 Zaman, S.A., Sarbini, S.R., 2015. The potential of resistant starch as a prebiotic. Crit. Rev. Biotechnol. $729 \quad$ 00, 1-7. https://doi.org/10.3109/07388551.2014.993590 